\title{
Nutraceuticals and cardiovascular risk: potential role of EPCs modulation
}

\author{
Rossella Russo ${ }^{1}$, Danela Lucchesi ${ }^{2}$, Vincenzo Longo ${ }^{1}$, Morena Gabriele ${ }^{1}$, Giuseppe Penno ${ }^{2}$, Laura Pucci ${ }^{1}$ \\ ${ }^{1}$ Institute of Agricultural Biology and Biotechnology, National Research Council, CNR, Pisa, 56124, Italy \\ ${ }^{2}$ Department of Clinical and Experimental Medicine, Section of Metabolic Diseases, University of Pisa, Pisa, 56124, Italy
}

Correspondence: Laura Pucci

E-mail: lauric16@yahoo.it

Received: August 07, 2015

Published online: September 22, 2015

\begin{abstract}
According to WHO cardiovascular diseases (CVDs) are the first cause of death in the world: more people die annually from CVDs than from any other cause. Vascular endothelium plays a pivotal role in the onset and progression of these pathologies and cardiovascular risk factors are frequently associated to the levels of endothelial progenitor cells (EPCs), bone marrow-derived circulating progenitors for the endothelial lineage. Since EPCs not only preserve vascular endothelium homeostasis, but might directly participate to re-endothelization and neovascularization, these cells represent an emerging protagonist in vascular competency and as such a cell model of great interest. An unhealthy diet is one of the main cardiovascular risk factor, while there is a great interest in the potential protective effects of "nutraceuticals", food-derived compounds that exert beneficial effects on human and animal health. The characterization of the endothelial effects of different nutraceuticals may provide fresh insights into their potential role in CVDs prevention. Several studies have already showed the protective effects of natural antioxidants on EPCs levels and functionality; some examples are resveratrol, catechin and folic acid. Fermentation has recently shown interesting roles in cardiovascular prevention since this process gave origin to a new class of foods, rich in bioactive compounds, the fermented foods. Consumption of fermented legumes and cereals, but also fermented beverages (such as beer and wine) was found to protect endothelial function through both lipid-lowering, as well anti-inflammatory and antioxidative mechanisms. Little is known about the effects of fermentation-derived nutraceuticals on EPCs. Given the important role of this cardiovascular biomarker, further analysis in this field can improve opportunities for CVDs prevention and treatment.
\end{abstract}

Keywords: endothelial function; endothelial progenitor cells; diet; antioxidants; cardiovascular diseases

To cite this article: $R$. Russo, et al. Nutraceuticals and cardiovascular risk: potential role of EPCs modulation. Stem Cell Transl Investig 2015; 2: e949. doi: 10.14800/scti.949.

\section{Vascular endothelium and EPCs: new insights}

For many years vascular endothelium has been considered a mere physical barrier between blood and underlying tissues; recent studies have demonstrated new and interesting roles of endothelium in vascular health ${ }^{[1]}$.

Endothelial cells composing this monolayer have therefore paracrine, endocrine and autocrine functions, by secreting several factors with vasodilatory and antiproliferative effects, such as endothelium-derived hyperpolarization factor (EDHF), nitric oxide (NO) and prostacyclin $\left(\mathrm{PGI}_{2}\right)$, and others inducing vasoconstrictor response, for instance endothelin-1 (ET-1), angiotensin II and reactive oxygen species (ROS) ${ }^{[2]}$.

These evidences make the vascular endothelium a multifunctional unit that regulates vascular homeostasis by 
maintaining the equilibrium between vasodilation and vasoconstriction; when this finely regulated balance is compromised, endothelium dysfunction occurs.

Beyond setting of vascular tone and integrity, the maintenance of vascular health includes also regulation of angiogenesis, hemostasis, immune and inflammatory responses, vascular growth and remodeling ${ }^{[2]}$.

One key actor in vascular repair and homeostasis, is the endothelial progenitor cell (EPC) system, bone marrow-derived circulating progenitors for the endothelial lineage, first described in 1997 by Asahara and colleagues ${ }^{[3]}$. EPCs circulate from bone marrow to incorporate into vascular endothelium and thus contribute to postnatal physiological and pathological neovascularization ${ }^{[4]}$. EPCs not only ensure the correct turnover of endothelial cells, but are also involved in the development, repair and regeneration of the systemic vasculature, as demonstrated by Prater and colleagues ${ }^{[5]}$. Indeed, in this study, authors suggest that postnatal neovascularization does not rely exclusively on sprouting from preexisting blood vessels (angiogenesis).

During the last decade, significant research has been performed to elucidate the physiological role of EPCs in tissue repair and to correlate these cells to several disease states.

EPCs are mainly located within the stem cell niche in bone marrow, along with some circulating populations in the peripheral blood. The process by which EPCs contribute to new vessel formation in adults consists of four interrelated steps. When injury or tissue damage occurs, EPCs are mobilized from the bone marrow into the circulation and home to tissue repair sites under the induction of signals such as hypoxia, growth factors, chemoattractant, and chemokines. EPCs then invade and migrate at the same sites, and differentiate into mature endothelial cells (ECs) and/or regulate pre-existing ECs via paracrine or juxtacrine signals [6]. These progenitors also improved the activity of endothelial NO synthase (eNOS), thereby restoring the correct functionality of endothelium ${ }^{[7,8]}$. The success of each step depends on the ability of EPCs to interact, adapt, and respond to multiple molecular stimuli ${ }^{[9]}$.

Thus EPCs, playing an important role in endothelium maintenance, re-endothelialization and neovascularization, represent an emerging actor involved in vascular fitness and as such a cell model of great interest ${ }^{[4]}$.

Despite the great enthusiasm aroused by these cells, several areas of controversy still persist in the study of EPCs, related to their identification, characterization and effective role in vascular biology. In particular, the lack of an unique and specific EPCs marker and the functional and phenotypical overlap between these cells and hematopoietic and mature endothelial cells, make it very difficult and controversial to define EPCs real identity ${ }^{[10]}$.

\section{Endothelium dysfunction and cardiovascular diseases: role of EPCs}

Functional impairment of vascular endothelium is found in cardiovascular diseases ${ }^{[11]}$ and also in patients with type 2 diabetes, insulin resistance and obesity ${ }^{[12]}$; therefore the integrity and functional properties of the endothelial monolayer play a critical role in atherogenesis, while cardiovascular risk factors induce endothelial injury and a cascade of pro-inflammatory events ${ }^{[13]}$.

As mentioned before endothelium dysfunction is caused by an imbalance between vasoconstrictor and vasodilator molecules, and between pro-atherogenic and anti-coagulant states ${ }^{[14]}$. This pathological condition is characterized by one or more of the following features: impaired NO bioavailability, increased oxidative stress, enhanced cell turnover, increased production of growth factor, over-expression of adhesion molecules and inflammatory genes, hemodynamic deregulation and increased permeability of the cell layer ${ }^{[15]}$.

Several factors contribute to the outcome of endothelial dysfunction, for example high levels of LDL cholesterol, glucose, insulin, triglycerides and omega- 6 to omega- 3 ratio, low concentration of HDL and Vitamin D and all wrong life habits ${ }^{[16]}$. Most of these factors are related to diet. This is why a dietary approach may reduce the risk of cardiovascular disease, also by affecting and ameliorating the endothelial function.

The endothelium is an important target for CVDs therapy, since it is rapidly exposed to systemically administered agents establishing a link with the underlying tissues ${ }^{[1]}$. Recent studies have shown a strong correlation between endothelial progenitor cells levels and cardiovascular risk; these cells have been indeed proposed as novel biomarker of endothelial function ${ }^{[17]}$. Accumulated evidences suggest that a balance between the damaged effects of cardiovascular risk factors and the ability of circulating progenitors to improve endothelial function, affects the cardiovascular risk ${ }^{[17-19]}$.

Decreased amounts of EPCs are correlated with atherosclerotic disease progression and increased cardiovascular risk, thus supporting an important role for endogenous vascular repair in modulating the clinical outcome of CAD. Age, sex, exercise, smoking, lipid profile, 
insulin resistance, inflammation, hypertension and genetic background have emerged as important factors correlated with EPCs number and function ${ }^{[20]}$. So, monitoring the levels of circulating EPCs as a surrogate biological marker might be specifically useful to identify novel approaches to enhance vascular repair capacity and thereby affect the progression of cardiovascular diseases ${ }^{[21]}$.

Several studies have shown the beneficial effect of drugs on EPCs, often isolated from patients with cardiovascular disease (CVD).

Treatment with statins, for example, leads to an increase in both number and functional activity of EPCs, thus contributing to the re-endothelization of damaged vessels ${ }^{[2]}$; moreover, a recent study of Fadini and colleagues showed that a brief statin withdrawal increases circulating EPCs and functional proangiogenic cells in T2D patients ${ }^{[23]}$. Treatment with sitagliptin, a dypeptidyl peptidase-4 inhibitor, increases the number of circulating $\mathrm{CD} 34^{+} \mathrm{CXCR} 4^{+}$cells, candidate markers for endothelial progenitor cells (EPCs) definition, by approximately 2-fold in patients with T2D ${ }^{[24]}$. Exendin-4, a human glucagon-like peptide 1 analogue, was shown to protect against ischemia in obese mice under hypoxic stress by enhancing angiogenesis capacity and circulating EPCs levels ${ }^{[25]}$.

Experimental evidence demonstrated an induction, by angiotensin-II, of senescence in endothelial progenitor, through an increase of oxidative stress; starting from these results, recent studies have shown the beneficial effect of the ACE inhibitors and also of angiotensin receptor blockers, on the mobilization and functional status of EPCs in conditions associated with vascular endothelial damage ${ }^{[26,27]}$. Spigoni and colleagues demonstrated that also pioglitazone, an insulin-sensitizing agent currently used in type 2 diabetic patients, is able to increase both viability and tubule formation capacity of endothelial progenitor cells isolated from pre-diabetic patients (patients with IGT impaired glucose tolerance) ${ }^{[28]}$. Continuous infusion of insulin in T1D patients enhances EPCs number, suggesting a novel mechanism of vascular damage by glucose fluctuations ${ }^{[29]}$.

Even treatment with erythropoietin seems to have beneficial effects on the functional properties of EPCs in both animals and humans ${ }^{[30]}$, while a study of Iwakura and colleagues showed an increase in the mobilization of EPCs after treatment with estradiol ${ }^{[31]}$.

\section{Endothelial health maintenance: the nutraceutical approach}

An "unhealthy" diet is one of the main causes of increased atherosclerotic cardiovascular disease in the industrialized countries. There is indeed a great interest in the potential cardiovascular protective effects of "nutraceuticals", food-derived substances that seems able to exert beneficial effects on health. Whether the endothelial dysfunction plays an important role in development and progression of atherosclerosis, the characterization of the endothelial effects of several nutraceuticals may provide important insights into their potential role in cardiovascular prevention ${ }^{[32]}$.

Several nutrients and phytochemicals in fruits and vegetables, including fiber, vitamins and antioxidant, could be independently or jointly responsible for the reduction in cardiovascular risk ${ }^{[33]}$. Since endothelial dysfunction is considered a risk factor for CVDs and an independent prognostic marker, maintaining correct endothelial function with dietary approaches has became a key therapeutic goal [34].

Dietary nitrite supplementation, for example, has been suggested to treat vascular aging, by reducing oxidative stress and inflammation thus preventing CVDs ${ }^{[35]}$, omega-3 fatty acid supplementation improves endothelial health reducing CVD risk ${ }^{[36]}$, while L-arginine, a precursor of NO synthesis, is able to normalize endothelial function when long-term administered ${ }^{[37]}$. Since oxidative stress is one of the major risk factor of endothelial dysfunction, several studied were performed using antioxidant molecules in healthy or ill subjects.

Antioxidant vitamin E and C supplementation showed an improvement of endothelial function in non-obese T2D subjects ${ }^{[38]}$, while vitamin $\mathrm{D}$ intake improved vasculature and kidney function in postmenopausal women ${ }^{[39]}$. Lipoic acid, a naturally occurring antioxidant, reduced serum glucose in diabetic patients ${ }^{[40]}$ and enhanced endothelial function in subjects with metabolic syndrome ${ }^{[41]}$.

Since EPCs play an essential role during endothelial homeostasis and repair, a healthy diet is probably able to affect endothelium health also by modulating the number and the functional activity of endothelial progenitors; active and functional EPCs are indeed able to better and faster counteract to all external stimuli and risk factors.

Ginkgo Biloba, for instance, showed in vitro beneficial effects on endothelial progenitors: treatment with its extract inhibits EPCs senescence, through augmentation of telomerase activity ${ }^{[42]}$. Moreover, folic acid supplementation modulates EPCs transcriptome in diabetic subjects ${ }^{[43]}$. Fish oil intake, in a different study, revealed no significant effect on vascular health ${ }^{[44]}$, while a recent research showed 
beneficial actions a of fish-oil supplementation on cellular markers of endothelial function: increased numbers of EPCs and reduced numbers of EMPs (endothelial microparticles), thus favoring the maintenance of endothelial integrity ${ }^{[45]}$.

Recent studies focused on polyphenols, a large class of natural compounds abundant in fruits, vegetables and spices. Several researches ${ }^{[46,47]}$ have found an inverse correlation between polyphenols assumption and CVD risk and mortality. In fact such healthy effects may explain the protective action on CVD exerted by food and beverages rich in polyphenols such as wine and tea or fruit juice ${ }^{[48,49]}$. The beneficial effects of polyphenols are mediated by many biochemical pathways; these compounds indeed improve endothelial function and increase NO release, modulate inflammation and lipid metabolism, protect against atherothrombotic events and platelet aggregation, and increase antioxidant status ${ }^{[33]}$. All these functions lead to normalization of vascular tone and also an overall antihypertensive effect ${ }^{[50]}$.

Epicatechin and catechin, two of the major and most investigated polyphenols, recently showed beneficial effects on patients with peripheral artery disease, by modulating endothelial activation induced by platelets, thus preventing atherosclerosis development ${ }^{[51]}$. A member of catechin family, epigallocatechin gallate, the most abundant polyphenol in green tea, seems to exert an insulin-mimetic action that counteract endothelial dysfunction and ameliorate insulin resistance in liver and skeletal muscle ${ }^{[52]}$. Since the main actions of polyphenols are based on their scavenging ability, recent both in vivo and in vitro studies focused on their protection from oxidative stress. Campos and colleagues, for example, showed that lemon grass polyphenols protect HUVECs (human umbilical vein endothelial cells) from oxidative stress induced by several stimuli ${ }^{[53]}$; another study analyzed the effects of olive oil polyphenols using an in vitro model that simulates T2D (ECV304 cells) and demonstrated that such compounds protect against endothelial dysfunction induced by high glucose and free fatty acids through modulation of nitric oxide and endothelin- ${ }^{[54]}$. Although several polyphenols are well known nowadays, the most famous is still resveratrol, an important antioxidant in red wine, which probably contributes to the potential of this beverage to prevent cardiovascular diseases. Wang and collaborators recently showed that this compound not only increases number and activity of endothelial progenitor cells, but also delays their senescence by enhancing telomerase activity ${ }^{[55,56]}$.

In recent years, many in vivo studies have been carried out, based on polyphenols-enriched diet; an improvement of endothelial function was shown in diabetic mice ${ }^{[57]}$, in hyperlipidemic rats ${ }^{[58]}$ and also in dyslipidemic pigs ${ }^{[59]}$.

Although the great interest on the single bioactive food component, such as resveratrol in wine, flavonoids in tea or allicin in garlic, one of the main challenge of agro-alimentary research is to understand the effective action of whole food on human and animal health, to further advice the composition of an healthy diet ${ }^{[60]}$. In order to fulfill this need, several clinical studies have been carried out to identify the different effects of single component and whole food, for example lycopene vs tomato ${ }^{[61]}$ or resveratrol vs red wine ${ }^{[62]}$, with controversial results. Therefore further studies need to be carried out to fully understand all individual and synergistic effects of food components.

\section{Fermented food: a new class of nutraceuticals?}

Shortly, the fermenting process can be defined as a set of chemical reactions that transform substances into simpler and more easily digestible compounds that activates digestive enzymes and friendly bacteria. This process has been always employed to get a new class of food, rich in bioactive compounds, the fermented food, which recently showed interesting roles in cardiovascular prevention.

Consumption of traditional fermented legumes, for example, has shown protective effects against CVD ${ }^{[63]}$; indeed, fermentation of legumes brings several advantages since it reduces the non-nutritional factors, improves nutrient digestibility and decreases their allergenicity ${ }^{[64]}$. This technological process also affects the biological functionality of legumes, as microbial enzymes perform the bioconversion of polyphenols into more active compounds ${ }^{[65,66]}$. A recent study showed that fermentation enhances the content of bioactive compounds in kidney bean extracts, thus encouraging the consumption of fermented legumes as a source of healthy substances ${ }^{[66]}$.

Phaseulus Vulgaris species, known to decrease both LDL-cholesterol and oxidative stress, well-known risk factors for CVD, and able to exert beneficial effects on short-term satiety and weight loss [67], demonstrated antistress and antioxidant effect in vivo when fermented ${ }^{[68]}$.

La Marca and colleagues showed that an extract obtained from a fermented powder of bean (Phaseolus vulgaris L.) tested on primary cultures of rat hepatocytes was able to regulate antioxidant and detoxifying enzymes through the Nrf2 pathway, inhibiting NF-kB activation and reducing $\mathrm{H}_{2} \mathrm{O}_{2}$-induced endoplasmic reticulum (ER) stress ${ }^{[69]}$. 
Recently, a Monascus-fermented rice extract was found to protect endothelial function through lipid-lowering, anti-inflammatory and antioxidative mechanisms; this extract also affects C-reactive protein concentration ${ }^{[70]}$.

Black tea, the fermented type of tea, was recently shown to protect against endothelial dysfunction through oxidative and endoplasmic reticulum stress modulation ${ }^{[71]}$.

Moreover, HPLC analysis of samples obtained from fermentation procedures showed that the level of major tea catechins epigallocatechin gallate (EGCG) and epicatechin gallate (ECG) dropped increasingly to about $1 / 3$ in the final product ${ }^{[72]}$. Also in kidney bean extracts HPLC analysis showed a huge increase of total bioactive compounds, in particular non-anthocyanin phenolic compounds, after fermentation ${ }^{[66]}$.

Epidemiological evidences demonstrate that moderate alcohol consumption, in particular of fermented beverages such as wine and beer, reduces the risk of morbidity and

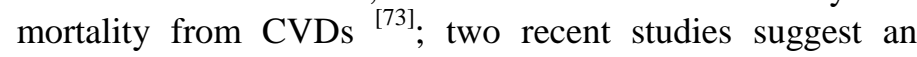
involvement of endothelial progenitor cells in these healthy effects. Indeed, Hang and colleagues, showed an improvement of number and functional activity of EPCs after red wine intake trough the enhancement of nitric oxide bioavailability ${ }^{[74]}$. In a further study, Chiva-Blanch and colleagues, compared the effects of moderate consumption of beer, non-alcoholic beer and gin on the number of circulating EPCs and EPC-mobilizing factors in subjects at high cardiovascular risk ${ }^{[75]}$; since non-alcoholic fraction of beer positively affects EPCs number, the authors suggested that the greater cardiovascular protection conferred by fermented beverage (such as beer or wine) is due to their high polyphenolic content.

A recent in vivo study, showed an augmentation of EPCs in healthy subjects after supplementation with a food supplement, Stem-Kine ${ }^{[76]}$, produced by fermentation of a combination of green tea, astralagus and goji berry extracts.

Another fermentation product, an extract of Zijuan Pu-erh tea, revealed an elevated antioxidant activity in vascular endothelial cells exposed to oxidative stress probably related to a different concentration of bioactive compounds such as polyphenols ${ }^{[77]}$. The same extract showed antiangiogenetic effects on HUVECs and anticancer activity on HT-29 cells [78].

Such evidences suggest a positive effect of food fermentation on endothelial progenitors number and functions.
In an our study EPCs treatment with a fermented grain, Lisosan G, increased not only viability but also cell function through the enhancement of antioxidative defenses, involving Nrf-2 pathway ${ }^{[79]}$. Whole grain cereals contain a lot of nutrients and bioactive substances that have health-promoting effects and epidemiological studies extensively demonstrated that whole grains consumption correlates with a reduced risk of type 2 diabetes and cardiovascular diseases ${ }^{[80]}$.

In our work, we explored the effects of Lisosan G. This product not only presents the above mentioned features of cereals, but is also enriched in bioactive compounds such as flavonoids, phenolic components and alpha-lipoic acid, since it derives from a fermentation process ${ }^{[81]}$. There, we evaluated the viability and cell function of endothelial progenitors and showed beneficial effects on both properties.

Lipoic acid (LA) is a natural antioxidant synthesized in the mitochondria which is able to directly scavenge ROS, chelate metals and react with, and regenerate, other antioxidants such as Vitamins $\mathrm{E}$ and $\mathrm{C}^{[82]}$; it also showed anti-inflammatory properties and is soluble both in fat and water which allows it to travel to and to enter all parts of the body ${ }^{[83]}$. Recent studies proposed LA as protective agent against CVDs outcome and progression, since it reinforces natural defenses and resistance to several types of stressors ${ }^{[84,85]}$. Although the mechanisms underlying these protective effects remain still unclear, a recent study of Ying and colleagues ${ }^{[86]}$ demonstrated that LA activates eNOS in endothelial cells in a PI3-kinase/Akt-dependent manner, thus counteracting endothelial dysfunction.

We further suggest that Lisosan $G$ ability to increase functional properties of this cardiovascular disease marker, is related to its components, such as linoleic and linolenic acids, alpha-lipoic acid, flavonoids and phenols.

\section{Conclusions}

The area of nutritional modulation of the stem cell compartment seems to offer significant benefit in treatment of a wide variety of cardiovascular, metabolic and degenerative diseases.

Fruits, cereals, legumes and vegetables are currently recognized as a source of antioxidant compounds that ameliorate EPCs viability and function, thus preventing endothelial dysfunction.

However, given the commercial pressures associated with this largely unregulated field, we suggest that detailed 
scientific investigations had to be performed before disease associated claims are released by the scientific community.

One area of recent interest in the biomedical field has been that of functional foods and nutraceuticals. While it is known that alteration of diet may modulate vascular responses, to our knowledge, little work as been reported to date on fermented foods and their capacity in improving levels and functions of circulating EPCs.

Fermentation is known to increase the bioavailability of minerals, proteins, peptides, antioxidants, flavanols and other organic molecules and several studies reported an association between fermented foods and human endothelial functionality and in particular EPC levels and function.

The mechanisms involved in these processes may be associated with a reduced production of free radicals and less oxidative stress, due to the protective effect of the antioxidant components of a fermented food rich diet.

In conclusion, consumption of fermented foods, enriching the diet of antioxidants thus reducing oxidative stress, improve the regenerative capacity of the endothelium as a result of a better balance between damage and repair.

\section{Conflict of interest}

The authors have no conflict of interest to declare.

\section{Acknowledgment}

This work was supported by a grant from Regione Toscana, Italy, Resolution 1157 (December 19, 2011), ID number D55E11002680005. The funders had no role in study design, data collection and analysis, decision to publish, or preparation of the manuscript.

\section{Abbreviations}

CVDs: cardiovascular diseases; EPCs: endothelial progenitor cells; NO: nitric oxide; ROS: reactive oxygen species; ALA: alpha-lipoic acid; T2D: type 2 diabetes; T1D: type 1 diabetes; HPLC: High Performance Liquid Chromatography; HUVECs: Human Umbilical Vein Endothelial Cells; EMPs: endothelial miniparticles; LDL: Low Density Lipoprotein; eNOS: endothelial nitric oxide synthase; ECs: endothelial cells.

\section{Authors contributions}

Contributed to the writing of the manuscript: RR. Contributed to the revision and submission of the manuscript: LP. Read and approved the final draft: DL, VL,
MG and GP.

\section{References}

1. Sena CM, Pereira AM, Seiça R. Endothelial dysfunction - a major mediator of diabetic vascular disease. Biochim Biophys Acta 2013; 1832: 2216-2231.

2. Félétou M. The Endothelium: Part 1: Multiple Functions of the Endothelial Cells-Focus on Endothelium-Derived Vasoactive Mediators. San Rafael (CA): Morgan \& Claypool Life Sciences 2011.

3. Asahara T, Murohara T, Sullivan A, Silver M, van der Zee R, Li t, et al. Isolation of putative endothelial progenitor cells for angiogenesis. Science 1997; 275: 964-967.

4. Asahara T, Masuda H, Takahashi T, Kalka C, Pastore C, Silver M, et al. Bone marrow origin of endothelial progenitor cells responsible for postnatal vasculogenesis in physiological and pathological neovascularization. Circ Res 1999; 85: 221-228.

5. Prater DN, Case J, Ingram DA, Yoder MC. Working hypothesis to redefine endothelial progenitor cells. Leukemia 2007; 21:1141-1149.

6. Gill M, Dias S, Hattori K, Rivera ML, Hicklin D, Witte L, et al. Vascular trauma induces rapid but transient mobilization of VEGFR2(+)AC133(+) endothelial precursor cells. Circ Res 2001; 88: 167-174.

7. Fujiyama S, Amano K, Uehira K, Yoshida M, Nishiwaki Y, Nozawa $\mathrm{Y}$, et al. Bone marrow monocyte lineage cells adhere on injured endothelium in a monocyte chemoattractant protein-1-dependent manner and accelerate reendothelialization as endothelial progenitor cells. Circ Res 2003; 93: 980-989.

8. Wassmann S, Werner N, Czech T, Nickenig G. Improvement of endothelial function by systemic transfusion of vascular progenitor cells. Circ Res 2006; 99: e74-83.

9. Balaji S, King A, Crombleholme TM, Keswani SG. The Role of Endothelial Progenitor Cells in Postnatal Vasculogenesis: Implications for Therapeutic Neovascularization and Wound Healing. Adv Wound Care (New Rochelle) 2013; 2: 283-295.

10. Timmermans F, Plum J, Yöder MC, Ingram DA, Vandekerckhove B, Case J. Endothelial progenitor cells: identity defined? J Cell Mol Med 2009; 13: 87-102.

11. Félétou M, Vanhoutte PM. Endothelial dysfunction: a multifaceted disorder (TheWiggers Award Lecture). Am J Physiol Heart Circ Physiol 2006; 291: H985-1002.

12. Wheatcroft SB, Williams IL, Shah AM, Kearney MT. Pathophysiological implications of insulin resistance on vascular endothelial function. Diabet Med 2003; 20: 255-268.

13. Schmidt C, Fagerberg B, Hulthe J. Non-stenotic echolucent ultrasound-assessed femoral artery plaques are predictive for future cardiovascular events in middle-aged men. Atherosclerosis 2005; 181: 125-130.

14. García-Morales V, Cuíñas A, Elíes J, Campos-Toimil M. PKA and Epac activation mediates cAMP-induced vasorelaxation by increasing endothelial NO production. Vascul Pharmacol 2014; 60: 95-101.

15. Taddei S, Ghiadoni L, Virdis A, Versari D, Salvetti A. Mechanisms of endothelial dysfunction: clinical significance and 
http://www.smartscitech.com/index.php/scti

preventive non-pharmacological therapeutic strategies. Curr Pharm Des 2003; 9: 2385-2402.

16. Grover-Páez F, Zavalza-Gómez AB. Endothelial dysfunction and cardiovascular risk factors. Diabetes Res Clin Pract 2009; 84: $1-10$.

17. J King TF, McDermott JH. Endothelial progenitor cells and cardiovascular disease. J Stem Cells 2014; 9: 93-106.

18. Fadini GP, Sartore S, Schiavon M, Albiero M, Baesso I, Cabrelle A, et al. Diabetes impairs progenitor cell mobilisation after hindlimb ischaemia-reperfusion injury in rats. Diabetologia 2006; 49: 3075-3084.

19. Vasa M, Fichtlscherer S, Aicher A, Adler K, Urbich C, Martin H, et al. Number and migratory activity of circulating endothelial progenitor cells inversely correlate with risk factors for coronary artery disease. Circ Res 2001; 89: E1-7.

20. Angelidi A, Melidonis A, Protopsaltis I, Sergentanis TN, Gritzapis A, Kornezos I, et al. Endothelial progenitor cells as a cardiometabolic risk factor marker in prediabetes. Hormones (Athens) 2014; 13: 244-251.

21. Schmidt-Lucke C, Rössig L, Fichtlscherer S, Vasa M, Britten M, Kämper U, et al, Reduced number of circulating endothelial progenitor cells predicts future cardiovascular events: proof of concept for the clinical importance of endogenous vascular repair. Circulation 2005; 111: 2981-2987.

22. Walter DH, Rittig K, Bahlmann FH, Kirchmair R, Silver M, Murayama T, et al. Statin therapy accelerates reendothelialization: a novel effect involving mobilization and incorporation of bone marrow-derived endothelial progenitor cells. Circulation 2002; 105: 3017-3024.

23. Fadini GP, Rigato M, Boscari F, Cappellari R, Menegazzo L, Pilutti C, et al. Short-term statin discontinuation increases endothelial progenitor cells without inflammatory rebound in type 2 diabetic patients. Vascul Pharmacol 2015; 67-69: 21-29.

24. Aso Y, Jojima T, Iijima T, Suzuki K, Terasawa T, Fukushima M, et al. Sitagliptin, a dipeptidyl peptidase- 4 inhibitor, increases the number of circulating CD34(+)CXCR4 $(+)$ cells in patients with type 2 diabetes. Endocrine 2015.

25. Sheu JJ, Chang MW, Wallace CG, Chiang HJ, Sung PH, Tsai TH, et al. Exendin-4 protected against critical limb ischemia in obese mice. Am J Transl Res 2015; 7: 445-459.

26. Min TQ, Zhu CJ, Xiang WX, Hui ZJ, Peng SY. Improvement in endothelial progenitor cells from peripheral blood by ramipril therapy in patients with stable coronary artery disease. Cardiovasc Drugs Ther 2004; 18: 203-209.

27. Bahlmann FH, de Groot K, Mueller O, Hertel B, Haller H, Fliser D. Stimulation of endothelial progenitor cells: a new putative therapeutic effect of angiotensin II receptor antagonists. Hypertension 2005; 45: 526-529.

28. Spigoni V, Picconi A, Cito M, Ridolfi V, Bonomini S, Casali C, et al. Pioglitazone improves in vitro viability and function of endothelial progenitor cells from individuals with impaired glucose tolerance. PLoS One 2012; 7: e48283.

29. Maiorino MI, Casciano O, Volpe ED, Bellastella G, Giugliano D, Esposito K. Reducing glucose variability with continuous subcutaneous insulin infusion increases endothelial progenitor cells in type 1 diabetes: an observational study. Endocrine 2015.
30. George J, Goldstein E, Abashidze A, Wexler D, Hamed S, Shmilovich $\mathrm{H}$, et al. Erythropoietin promotes endothelial progenitor cell proliferative and adhesive properties in a PI 3-kinase-dependent manner. Cardiovasc Res 2005; 68: 299-306.

31. Iwakura A, Shastry S, Luedemann C, Hamada H, Kawamoto A, Kishore R, et al. Estradiol enhances recovery after myocardial infarction by augmenting incorporation of bone marrow-derived endothelial progenitor cells into sites of ischemia-induced neovascularization via endothelial nitric oxide synthase-mediated activation of matrix metalloproteinase-9. Circulation 2006; 113: 1605-1614.

32. Zuchi C, Ambrosio G, Lüscher TF, Landmesser U. Nutraceuticals in cardiovascular prevention: lessons from studies on endothelial function. Cardiovasc Ther 2010; 28:187-201.

33. Badimon L, Vilahur G, Padro T. Nutraceuticals and atherosclerosis: human trials. Cardiovasc Ther 2010; 28: 202-215.

34. Van Craenenbroeck EM, Conraads VM. Endothelial progenitor cells in vascular health: focus on lifestyle. Microvasc Res 2010; 79: 184-192.

35. Sindler AL, Devan AE, Fleenor BS, Seals DR. Inorganic nitrite supplementation for healthy arterial aging. J Appl Physiol 2014; 116: $463-477$.

36. Wang Q, Liang X, Wang L, Lu X, Huang J, Cao J, et al. Effect of omega-3 fatty acids supplementation on endothelial function: a meta-analysis of randomized controlled trials. Atherosclerosis 2012; 221: 536-543.

37. Böger RH. The pharmacodynamics of L-arginine. Altern Ther Health Med 2014; 20: 48-54.

38. Montero D, Walther G, Stehouwer CD, Houben AJ, Beckman JA, Vinet A. Effect of antioxidant vitamin supplementation on endothelial function in type 2 diabetes mellitus: a systematic review and meta-analysis of randomized controlled trials. Obes Rev 2014; 15: 107-116.

39. Liu ZM, Woo J, Wu SH, Ho SC. The role of vitamin D in blood pressure,endothelial and renal function in postmenopausal women. Nutrients 2013; 5: 2590-2610.

40. Packer L, Kraemer K, Rimbach G. Molecular aspects of lipoic acid in the prevention of diabetes complications. Nutrition 2001; 17: 888-895.

41. Sola S, Mir MQ, Cheema FA, Khan-Merchant N, Menon RG, Parthasarathy $\mathrm{S}$, et al. Irbesartan and lipoic acid improve endothelial function and reduce markers of inflammation in the metabolic syndrome: results of the Irbesartan and Lipoic Acid in Endothelial Dysfunction (ISLAND) study. Circulation 2005; 111:343-348.

42. Dong XX, Hui ZJ, Xiang WX, Rong ZF, Jian S, Zhu CJ. Ginkgo biloba extract reduces endothelial progenitor-cell senescence through augmentation of telomerase activity. J Cardiovasc Pharmacol 2007; 49: 111-115.

43. Van Oostrom O, de Kleijn DP, Fledderus JO, Pescatori M, Stubbs A, Tuinenburg A, et al. Folic acid supplementation normalizes the endothelial progenitor cell transcriptome of patients with type 1 diabetes: a case-control pilot study. Cardiovasc Diabetol 2009; 8: 47.

44. Wong CY, Yiu KH, Li SW, Lee S, Tam S, Lau CP, et al. Fish-oil supplement has neutral effects on vascular and metabolic function but improves renal function in patients with Type 2 diabetes 
http://www.smartscitech.com/index.php/scti

mellitus. Diabet Med 2010; 27: 54-60.

45. Wu SY, Mayneris-Perxachs J, Lovegrove JA, Todd S, Yaqoob P. Fish-oil supplementation alters numbers of circulating endothelial progenitor cells and microparticles independently of eNOS genotype. Am J Clin Nutr 2014; 100: 1232-1243.

46. Hirvonen T, Pietinen P, Virtanen M, Ovaskainen ML, Häkkinen S, Albanes D, et al. Intake of flavonols and flavones and risk of coronary heart disease in male smokers. Epidemiology 2001; 12: 62-67.

47. Ríos-Hoyo A, Cortés MJ, Ríos-Ontiveros H, Meaney E, Ceballos G, Gutiérrez-Salmeán G. Obesity, Metabolic Syndrome, and Dietary Therapeutical Approaches with a Special Focus on Nutraceuticals (Polyphenols): A Mini-Review. Int J Vitam Nutr Res 2014; 84: 113-123.

48. Flammer AJ, Martin EA, Gössl M, Widmer RJ, Lennon RJ, Sexton JA, et al. Polyphenol-rich cranberry juice has a neutral effect on endothelial function but decreases the fraction of osteocalcin-expressing endothelial progenitor cells. Eur J Nutr 2013; 52: 289-296.

49. Felice F, Zambito Y, Di Colo G, D'Onofrio C, Fausto C, Balbarini A, et al. Red grape skin and seeds polyphenols: Evidence of their protective effects on endothelial progenitor cells and improvement of their intestinal absorption. Eur J Pharm Biopharm 2012; 80: 176-184.

50. Rodrigo R, Gil D, Miranda-Merchak A, Kalantzidis G. Antihypertensive role of polyphenols. Adv Clin Chem 2012; 58: 225-254.

51. Carnevale R, Loffredo L, Nocella C, Bartimoccia S, Bucci T, De Falco E, et al. Epicatechin and catechin modulate endothelial activation induced by platelets of patients with peripheral artery disease. Oxid Med Cell Longev 2014; 2014: 691015.

52. Keske MA, Ng HL, Premilovac D, Rattigan S, Kim JA, Munir K, et al. Vascular and metabolic actions of the green tea polyphenol epigallocatechin gallate. Curr Med Chem 2015; 22: 59-69.

53. Campos J, Schmeda-Hirschmann G, Leiva E, Guzmán L, Orrego R, Fernández P, et al. Lemon grass (Cymbopogon citratus (D.C) Stapf) polyphenols protect human umbilical vein endothelial cell (HUVECs) from oxidative damage induced by high glucose, hydrogen peroxide and oxidised low-density lipoprotein. Food Chem 2014; 151: 175-181.

54. Storniolo CE, Roselló-Catafau J, Pintó X, Mitjavila MT, Moreno JJ. Polyphenol fraction of extra virgin olive oil protects against endothelial dysfunction induced by high glucose and free fatty acids through modulation of nitric oxide and endothelin-1. Redox Biol 2014; 2C: 971-977.

55. Wang XB, Huang J, Zou JG, Su EB, Shan QJ, Yang ZJ, et al. Effects of resveratrol on number and activity of endothelial progenitor cells from human peripheral blood. Clin Exp Pharmacol Physiol 2007; 34:1109-1115.

56. Wang XB, Zhu L, Huang J, Yin YG, Kong XQ, Rong QF, et al. Resveratrol-induced augmentation of telomerase activity delays senescence of endothelial progenitor cells. Chin Med J 2011; 124: 4310-4315.

57. Taguchi K, Hida M, Matsumoto T, Ikeuchi-Takahashi Y, Onishi $\mathrm{H}$, Kobayashi $\mathrm{T}$. Effect of short-term polyphenol treatment on endothelial dysfunction and thromboxane A2 levels in streptozotocin-induced diabetic mice. Biol Pharm Bull 2014; 37: 1056-1061.
58. Zuo X, Tian C, Zhao N, Ren W, Meng Y, Jin X, et al. Tea polyphenols alleviate high fat and high glucose-induced endothelial hyperpermeability by attenuating ROS production via NADPH oxidase pathway. BMC Res Notes 2014; 7: 120.

59. Vilahur G, Padró T, Casaní L, Mendieta G, López JA, Streitenberger $\mathrm{S}$, et al. Polyphenol-enriched Diet Prevents Coronary Endothelial Dysfunction by Activating the Akt/eNOS Pathway. Rev Esp Cardiol (Engl Ed) 2015; 68: 216-225.

60. Burton-Freeman B, Sesso HD. Whole food versus supplement: comparing the clinical evidence of tomato intake and lycopene supplementation on cardiovascular risk factors. Adv Nutr 2014; 5: 457-485.

61. Wang Z, Huang Y, Zou J, Cao K, Xu Y, Wu JM. Effects of red wine and wine polyphenol resveratrol on platelet aggregation in vivo and in vitro. Int J Mol Med 2002; 9: 77-79.

62. Crujeiras AB, Parra D, Abete I, Martínez JA. A hypocaloric diet enriched in legumes specifically mitigates lipid peroxidation in obese subjects. Free Radic Res 2007; 41: 498-506.

63. Starzyńska-Janiszewska A, Stodolak B, Mickowska B. Effect of controlled lactic acid fermentation on selected bioactive and nutritional parameters of tempeh obtained from unhulled common bean (Phaseolus vulgaris) seeds. J Sci Food Agric 2014; 94: 359-366.

64. Martinez-Villaluenga C, Torino MI, Martín V, Arroyo R, Garcia-Mora P, Estrella Pedrola I, et al. Multifunctional properties of soy milk fermented by Enterococcus faecium strains isolated from raw soy milk. J Agric Food Chem 2012; 60: 10235-10244.

65. Torino MI, Limón RI, Martínez-Villaluenga C, Mäkinen S, Pihlanto A, Vidal-Valverde C, et al. Antioxidant and antihypertensive properties of liquid and solid state fermented lentils. Food Chem 2013; 136: 1030-1037.

66. Limón RI, Peñas E, Torino MI, Martínez-Villaluenga C, Dueñas M, Frias J. Fermentation enhances the content of bioactive compounds in kidney bean extracts. Food Chem 2015; 172: 343-352.

67. Hutchins AM, Winham DM, Thompson SV. Phaseolus beans: impact on glycaemic response and chronic disease risk in human subjects. Br J Nut 2012; 108: S52-65.

68. Yeap SK, Beh BK, Ali NM, Mohd Yusof H, Ho WY, Koh SP, et al. In vivo antistress and antioxidant effects of fermented and germinated mung bean. Biomed Res Int 2014; 2014: 694842.

69. La Marca ML, Pucci L, Bollini R, Russo R, Sparvoli F, Gabriele $\mathrm{M}$, et al. Antioxidant effect of a fermented powder of Lady Joy bean in primary rat hepatocytes. Cell Mol Biol Lett 2015; 20: 102-116.

70. Lin CP, Lin YL, Huang PH, Tsai HS, Chen YH. Inhibition of endothelial adhesion molecule expression by Monascus purpureus-fermented rice metabolites, monacolin K, ankaflavin, and monascin. J Sci Food Agric 2011; 91: 1751-1758.

71. San Cheang W, Yuen Ngai C, Yen Tam Y, Yu Tian X, Tak Wong $\mathrm{W}$, Zhang $\mathrm{Y}$, et al. Black tea protects against hypertension-associated endothelial dysfunction through alleviation of endoplasmic reticulum stress. Sci Rep 2015; 5: 10340.

72. Zhu YF, Chen JJ, Ji XM, Hu X, Ling TJ, Zhang ZZ, et al. Changes of major tea polyphenols and production of four new B-ring fission metabolites of catechins from post-fermented Jing-Wei Fu brick tea. Food Chem 2015; 170: 110-117. 
73. Rimm EB, Klatsky A, Grobbee D, Stampfer MJ. Review of moderate alcohol consumption and reduced risk of coronary heart disease: is the effect due to beer, wine, or spirits. BMJ 1996; 312: 731-736.

74. Huang PH, Tsai HY, Wang CH, Chen YH, Chen JS, Lin FY, et al. Moderate intake of red wine improves ischemia-induced neovascularization in diabetic mice--roles of endothelial progenitor cells and nitric oxide. Atherosclerosis 2010; 212: 426-435.

75. Chiva-Blanch G, Condines X, Magraner E, Roth I, Valderas-Martínez P, Arranz S, et al. The non-alcoholic fraction of beer increases stromal cell derived factor 1 and the number of circulating endothelial progenitor cells in high cardiovascular risk subjects: a randomized clinical trial. Atherosclerosis 2014; 233: 518-524.

76. Mikirova NA, Jackson JA, Hunninghake R, Kenyon J, Chan KW, Swindlehurst CA, et al. Nutraceutical augmentation of circulating endothelial progenitor cells and hematopoietic stem cells in human subjects. J Transl Med 2010; 8: 34.

77. Fan JP, Fan C, Dong WM, Gao B, Yuan W, Gong JS. Free radical scavenging and anti-oxidative activities of an ethanol-soluble pigment extract prepared from fermented Zijuan Pu-erh tea. Food Chem Toxicol 2013; 59:527-533.

78. Zhao X, Song JL, Kim JD, Lee JS, Park KY. Fermented Pu-erh tea increases in vitro anticancer activities in HT-29 cells and has antiangiogenetic effects on HUVECs. J Environ Pathol Toxicol Oncol 2013; 32: 275-288.

79. Lucchesi D, Russo R, Gabriele M, Longo V, Del Prato S,
Penno G, et al. Grain and bean lysates improve function of endothelial progenitor cells from human peripheral blood: involvement of the endogenous antioxidant defenses. PLoS One 2014; 9: e109298.

80. Malaguti M, Dinelli G, Leoncini E, Bregola V, Bosi S, Cicero AF, et al. Bioactive Peptides in Cereals and Legumes: Agronomical, Biochemical and Clinical Aspects. Int J Mol Sci 2014; 15: 21120-21135.

81. La Marca M, Beffy P, Pugliese A, Longo V. Fermented wheat powder induces the antioxidant and detoxifying system in primary rat hepatocytes. PLoS One 2013; 8: e83538.

82. Singh U, Jialal I. Alpha-lipoic acid supplementation and diabetes. Nutr Rev 2008; 66: 646-657.

83. Segall A, Sosa M, Alami A, Enero C, Hormaechea F, Pizzorno MT, et al. Stability study of lipoic acid in the presence of vitamins $\mathrm{A}$ and $\mathrm{E}$ in o/w emulsions for cosmetic application. J Cosmet Sci 2004; 55: 449-461.

84. Wollin SD, Jones PJ. Alpha-lipoic acid and cardiovascular disease. J Nutr 2003; 133: 3327-3330.

85. Skibska B, Goraca A. The protective effect of lipoic acid on selected cardiovascular diseases caused by age-related oxidative stress. Oxid Med Cell Longev 2015; 2015: 313021.

86. Ying Z, Xie X, Chen M, Yi K, Rajagopalan S. Alpha-lipoic acid activates eNOS through activation of PI3-kinase/Akt signaling pathway. Vascul Pharmacol 2015; 64: 28-35. 